\title{
Scholarly Communication in Developmental Dyslexia: Influence of Network Structure on Change in a Hybrid Problem Area
}

\author{
Claudia A. Perry* \\ Educational Information Services, State University of New York College of Optometry, 100 East 24th St., \\ New York, NY 10010-3677. E-mail: cperry@sunyopt.edu \\ Ronald E. Rice \\ School of Communication, Information \& Library Studies, Rutgers University, 4 Huntington St., \\ New Brunswick, NJ 08903-5067. E-mail: rrice@scils.rutgers.edu
}

\begin{abstract}
Based on Mulkay's and Kuhn's models of change in scientific structure, a scientific communication model of the emergence of a hybrid research area was developed and tested in the field of developmental dyslexia. Data included co-citation data on 74 dyslexia researchers at three points in time, who-to-whom communication network data, survey responses, resumes, association and biographical sources, online reference and citation databases, publications, grant databases, and telephone interviews. Researchers were partitioned into "blocks" of similar scientists on the basis of co-citation and communication relations, compared on selected network-level and individual-level characteristics in order to validate block labels, and situated historically in the politics and advances surrounding the problem area. Results show support for Mulkay's model of branching instead of Kuhn's model of scientific revolution. Evidence points to divergence rather than convergence among the related research areas, but suggests the need for longitudinal follow-up in order to rule out the impact of the inertia of aggregate co-citation data. Implications for theory, methodology, and research are discussed.
\end{abstract}

\section{Introduction}

Interaction among researchers representing differing perspectives and disciplinary backgrounds, even those investigating similar problems, may result in a variety of outcomes, such as the emergence of innovative and new research communities (convergence), mutual distancing (divergence), or no change at all. For example, Rogers

* To whom all correspondence should be addressed.

Received November 5, 1996; revised March 3, 1997; accepted March 3, 1997

(C) 1998 John Wiley \& Sons, Inc. and Cottrill (1990, p. 163) note that despite a common focus on technological innovation and certain points of intersection among selected authors, the literatures of technology transfer and the diffusion of innovations remain relatively distinct. Similarly, Borgman and Rice (1992) find less bibliometric evidence for convergence between the literatures of information science and communication than other commentators suggest, although citation links between the areas appear to be increasing over time. Such changes (or stability) in scientific structures may have implications for the reception of interdisciplinary research (e.g., see Pierce, 1990), the development of departmental structures and scholarly publishing (see Borgman \& Rice, 1992), the discovery of new knowledge (see Swanson, 1990), and improved theoretical understanding of the process of change in science.

Citation studies are only one approach to studying the process of change in scholarly fields. Others include historical research, ethnographic case studies, and many other techniques. But citation studies can be particularly useful in establishing a "map" for subsequent interpretation, as Lievrouw (1990, p. 69) points out. Citation and co-citation methods are especially valuable as part of a set of multiple indicators in a triangulation approach. McCain (1989) notes that "well-designed co-cited author studies can go beyond the knowledge and insights available from even the most knowledgeable, well-connected single researcher in the field"' (p. 677). White (1990) observes that the use of authors as the unit of analysis permits investigation of both the perceived cognitive and social structures of science, commenting that this possible interrelationship "has received less systematic attention than it deserves" (p. 86; although see Lievrouw, Rogers, Lowe, \& Nadel, 1987). 
The present study examines this question of structural change (particularly convergence) in the area of developmental dyslexia research. Dyslexia research is of interest, in part, because of its hybrid character, involving researchers coming from a wide variety of backgrounds, disciplines, and professions. Further, it is an area in which one can profitably compare and contrast intellectual and social networks, since change appears to be ongoing and major research advances have recently been announced. In addition, dyslexia is a substantial societal problem, it has been the focus of major targeted research funding, and it has received a good deal of attention in the media. ${ }^{1}$

A problem area is "the accepted knowledge and recognized questions associated with a substantive object of study or with an instrumental means of inquiry" (Gieryn, 1978, p. 97). A problem area will potentially overlap with a social community of researchers (problem network), but the cognitive and social networks are not necessarily the same (see Lievrouw et al., 1987), nor are they expected to remain frozen at a single point in time. Following the principle of homophily (Rogers, 1983, p. 18 ), clearly ideas tend to circulate more easily within a research or problem area than across disciplinary boundaries. However, social factors may present obstacles to communication and flows of information even within the same problem area (Restivo \& Loughlin, 1987). A hybrid problem area represents the range of evolving knowledge and relevant questions recognized by researchers of potentially varying backgrounds concerned with the same substantive object of study. The problem network examined here will be developmental dyslexia: Specifically, those researchers with roots in the phonological deficit and visual perceptual deficit perspectives, and recent migrants from the neurosciences and other fields.

\section{Change and Innovation in Problem Areas and Networks}

\section{Models of Scientific Change: Revolution or Evolution}

A well-known model of scientific change was advanced by Thomas Kuhn in The Structure of Scientific Revolutions (1970). Scientific discovery and change follow a particular pattern: Awareness of an anomaly, gradual emergence of recognition, consequent change of paradigm categories and procedures, and resistance. This leads to a growing state of crisis that is ultimately resolved by "large-scale paradigm destruction"' (p. 67).

Mulkay, Gilbert, and Woolgar (1975; Mulkay, 1976) suggest a more evolutionary model of scientific branching, in which Kuhnian-style revolution can be

\footnotetext{
${ }^{1}$ This article reports on findings relating to changes in social and intellectual network structures in dyslexia research over time; a separate article examines the characteristics of networks and network members that might differentially affect involvement in the problem area (Perry \& Rice, 1997).
}

viewed as a special case. A new research network may emerge following the migration of researchers who are attracted by unsolved problems or developments, outside, but related to, their present research area, especially where theories and techniques transfer readily to another problem area. This sets off a cycle of exploration, unification, and decline/displacement. Over time, the availability of new techniques, theory and advances in research may lead to increased acceptability of a new or less favored perspective within the wider scientific community (Rappa \& Debackere, 1995). Theoretical advances may provide a means of reconciling disparate results and views within an integrative framework (e.g., see Rayner, 1993; Stanovich, 1993; Tallal, Galaburda, Llinas, \& von Euler, 1993).

Whitley (1984) notes that Kuhn's unitary model of knowledge development does not take into account how different sorts of knowledge are produced in different social contexts (p. 4), viewing intellectual fields as a variety of work organizations. All three approaches (Kuhn, Mulkay, Whitley) are examples of a sociocultural model of the dynamics of science, as compared to models that emphasize the importance of rational knowledge, competition, or the extended translation of statements (Callon, 1995). Each model to some extent builds upon and extends its predecessors, but also focuses attention on different questions. The sociocultural model is especially appropriate for the examination of scholarly communication patterns at the macro-level of relations, an area of particular interest when examining change in hybrid fields such as developmental dyslexia.

\section{Scientific Networks and the Social Context of Change}

In both the Kuhnian approach and the model of branching, the notion of scientific community is central, although Whitley notes that specialist communities may be relatively unimportant or non-existent in some areas (1984, p. 164). Characterized by relatively similar values and the development over time of shared intellectual and technical standards, scientific community is created and sustained by extensive communication among its members within and across their networks (e.g., Chubin, 1976, 1985; Crane, 1972; Gieryn, 1978; Kuhn, 1970; Mulkay, 1976, 1977). However, the bulk of this work is descriptive, its findings are not easily tested, it has focused on either cognitive or social factors in the life cycle of a specialty or problem area rather than providing a holistic view of the process, and it seldom distinguishes between the scientists' informal communication network and the formal content and citation network (as Lievrouw et al., 1987, emphasize).

The emergence of a new perspective in a problem area from other pre-existing perspectives may be reflected in changing perceptions of formal relevance (e.g., co-citation patterns), changing patterns of intellectual involvement (e.g., publication), and changing patterns of infor- 
mal social interaction (such as the organization of, and attendance at, conferences on topics of interest to a hybrid audience). Especially in an area of rapid change, measures of formal communication and informal communication may not correspond. Alternative intellectual perspectives in a problem area will be reflected in separate (formal) co-citation networks (Lievrouw et al., 1987), and possibly separate (informal) social networks (Mulkay et al., 1975). Formal network refers to exchange through formal, archival channels, such as journals, print or electronic publications, and citations among such publications. Informal networks refers to information exchange through interpersonal channels, including conversation, conference presentations, and E-mail. These two networks may overlap to some degree (Garvey, 1979). Members of an established network will tend to have accumulated a large number of citations to their work over time, to be better known within the scientific community (Mulkay et al., 1975), and to cite each other and cocite similar sets of others (which suggest the intellectual structure of a problem area; McCain, 1990a). They may exercise considerable influence on the reception-either positive or negative-accorded research from an alternative perspective (Rappa \& Debackere, 1995). Their research is expected to be consistent with the dominant paradigm, and will likely be published in a relatively limited number of journals. In contrast, articles published by members of an emerging network may be scattered among a variety of journals or among less visible journals (Mulkay et al., 1975), which may not yet be widely indexed. The dispersion of published research tends to isolate the emerging perspective from the more established perspective and from the scholarly community at large. It also makes it difficult to stay abreast of current developments, thus increasing the relative importance of informal contacts in communicating information in the emerging group.

\section{The Case of Developmental Dyslexia}

Developmental dyslexia is an example of a problem area of interest to a wide variety of researchers, with backgrounds ranging from education to neuroscience. Dyslexia is an "unexpected difficulty in learning to read and spell"' (Pennington, 1991, p. 45), or more formally, the "selective impairment of reading skills despite normal intelligence, sensory acuity, motivation and instruction"' (Livingstone, Rosen, Drislane, \& Galaburda, 1991, p. 7943 ). There are many subtleties and controversies in available definitions, and consequently also a lack of consensus on the number of individuals affected (Rayner \& Pollatsek, 1989; Solan, 1993). Recent estimates of the prevalence of developmental reading disability range from 3 to $14 \%$ of the population (Shaywitz, Shaywitz, Fletcher, \& Escobar, 1990). Even with lower estimates, dyslexia clearly affects the lives of many individuals.
The most commonly accepted explanations for dyslexia have revolved around a linguistic, or phonological deficit theory (a difficulty in decoding words) and a visual perceptual deficit hypothesis (involving problems in processing visual stimuli) hotly debated in the Journal of Learning Disabilities in the late 1970s (Fletcher \& Satz, 1979a, 1979b; Vellutino, 1979; Vellutino, Steger, Moyer, Harding, \& Niles, 1977). By the mid-1980s, the research began to coalesce around a small set of general conclusions that are endorsed by the vast majority of researchers. The most fundamental is that word decoding ability, primarily the result of differences in phonological abilities, accounts for a very large proportion of the variance in reading ability at all levels (Stanovich, 1985, p. 67). In spite of a serious effort by Lovegrove, Martin, and Slaghuis (1986) to prove that a visual deficit exists in a large percentage of specifically disabled readers, the phonological point of view was further advanced in a widely read Scientific American article (Vellutino, 1987).

The debate was undoubtedly exacerbated by rivalries between two professions concerned with the delivery of eye care-optometry and ophthalmology-influenced by differences in treatment advocacy (American Academy of Ophthalmology, 1987; Flax, Mozlin, \& Solan, 1984); legislative efforts have enlarged the scope of optometric practice to include the diagnostic and therapeutic use of drugs, and an overabundance of ophthalmologists (Noreika, 1990).

In recent years, however, there has been renewed interest in the visual perceptual component to reading disability (e.g., Eden, Stein, Wood, \& Wood, 1995; Kruk, 1991; Lehmkuhle, Garzia, Turner, Hash, \& Baro, 1993) following advances in the neurobiological, genetic, cognitive and neuropsychological aspects of dyslexia (Galaburda, 1993), and the proposal that underlying deficits in temporal processing may account for both phonological (linguistic) as well as visual and auditory perceptual problems in developmental disabilities (Tallal et al., 1993). It is likely that these efforts were spurred in large part by a major increase in federal funding of research into the biological basis of learning disabilities. For example, funding for learning disabilities from the National Institutes of Health (NIH) increased from $\$ 1.75$ million in 1975 to $\$ 10.42$ million in 1990 , for a cumulative total of $\$ 76$ million (Lyon, 1991).

In this study, visual dyslexia or neuroscience-vision network will designate researchers whose work has been concerned primarily with topics related to visual or spatial and/or neuroscientific aspects or processes in the developmentally reading disabled (e.g., Lovegrove et al., 1986). Phonological dyslexia network will refer to those whose work has been chiefly concerned with the role of linguistic processing in developmental reading disability (e.g., Vellutino, 1987). Emerging hybrid network will denote those whose work incorporates or accepts aspects of both perspectives (e.g., Rayner, 1993). 


\section{Research Questions and Hypotheses}

Three research questions and hypotheses derived from the prior discussions follow. They are concerned with (1) the existence of possible networks within the problem area, (2) possible changes within those networks over time, and (3) their social and intellectual structures. ${ }^{2}$

The time periods referred to correspond to identifiable periods of change in the problem area: $\mathrm{T} 1=1976-1981$; $\mathrm{T} 2=1982-1987$; and T3 $=1988-1993$. Major federal funding of learning disabilities research began in 1979 with the establishment of the "Colorado Reading Project" at the University of Colorado. Additional multidisciplinary projects received funding in 1986, 1987, 1989, and 1990. Allowing 2 years for funding to have some impact, the grant patterns appeared to fall into an early, middle, and late pattern, in which one might anticipate an increasing impact of the funded research in each of the three time periods. In addition, the series of articles debating the perceptual deficit hypothesis (Fletcher \& Satz, 1979a, 1979b; Vellutino, 1979; Vellutino et al., 1977) were published in T1, the review articles presenting the alternative perspectives (Lovegrove et al., 1986; Stanovich, 1985) were published in T2, and the articles reflecting recent developments in neurobiological aspects of learning disabilities were published in T3. Further, the years included in T3 happened to coincide with the subset of the SciSearch database available at the time of this analysis.

\section{Research Question 1}

Are Alternative Intellectual Networks (Established vs. Emerging) in a Problem Area Associated with Different CoCitation Patterns? H1a. Neuroscience-vision and phonological dyslexia researchers are associated with separate co-citation blocks associated with time periods $\mathrm{T} 1-\mathrm{T} 2-\mathrm{T} 3$.

$\mathrm{H} 1 \mathrm{~b}$. In the co-citation network structure, phonological dyslexia researchers are more highly co-cited with other network members than are neuroscience-vision researchers (T1, T3).

H1c. In the social network structure, phonological dyslexia researchers are more highly co-cited with other network members than are neuroscience-vision researchers (T3).

\section{Research Question 2}

Has the Formal Perceived (Citation) Relationship Between Alternative Perspectives in the Problem Area Changed Over Time? H2a. The co-citation blocks of neuroscience-vision dyslexia and phonological dyslexia researchers become less separate over time (T1-T2-T3).

$\mathrm{H} 2 \mathrm{~b}$. The degree of intellectual linkage (mean co-citation strength) in the problem area increases over time (T1-T2-T3).

\section{Research Question 3}

Is Convergence Taking Place Between Researchers from Alternative Perspectives? H3. The social communication net-

\footnotetext{
${ }^{2}$ As noted previously, a separate article addresses characteristics of the proposed networks and network members ( see Perry \& Rice, 1997).
}

work in the problem area at T3 includes blocks of individuals from the neuroscience-vision dyslexia co-citation networks (from T1 and T3) and from the phonological dyslexia co-citation networks (from $\mathrm{T} 1$ and $\mathrm{T} 3$ ).

\section{Method}

This section examines the various approaches used to collect and analyze data in the study.

\section{Network Identification}

As Laumann, Marsden, and Prensky (1983) point out, the specification of system boundaries is an issue of central importance in the design of network studies. From a network perspective, "individual behavior is viewed as at least partially contingent on the nature of an actor's social relationships to certain key others"' (p. 18), so it is essential that care is given to the inclusion rules used in specifying the members of actors in a network. Misspecification of the network may result in a fundamental misrepresentation of the process under study. In the case of a study involving both formal (citation) and informal (social) network structure, it is necessary that inclusion rules consider the existence of both formal and informal links among the individuals in the problem network.

The target networks were selected, in part, because of a series of published exchanges in the literature. Substantial review articles made the existence of opposing perspectives on the underlying causes of dyslexia more clearly discernible, and the proponents of such alternative research approaches more readily identifiable than is often the case ( see, for example, Benton, 1985; Fletcher \& Satz, 1979a, 1979b; Vellutino, 1979, 1987; Vellutino et al., 1977). Further, the publication of such articles in more than one source, and by a variety of authors, suggested that the published perspectives reflected a broad controversy within the field, rather than personal animosities or prejudices held by a few individuals.

Multiple indicators were used in an effort to ensure that individuals selected were considered central to the broadly construed problem area, where possible, both in a social and cognitive sense. These included presence in relevant bibliographies over a 20 -year period, lists of attendance or participation in relevant conferences, presence on advisory and editorial boards pertaining to learning disabilities, and lists of principal investigators of recently funded research grants in dyslexia.

Of the 924 names identified using these various sources, 69 were mentioned in four or more sources, with a few exceptions. ${ }^{3}$ An additional 50 researchers men-

\footnotetext{
${ }^{3}$ Individuals holding grants in multiple years, but mentioned in one or fewer of the other sources, were not included; a colleague of the senior author was excluded because of his knowledge of the nature of the study. Isabelle Y. Liberman was selected for inclusion in the study despite the fact that she is deceased, because she was a central figure in dyslexia research for many years, and did co-author with her husband Alvin M. Liberman. All other names were deleted from the list if the researcher was deceased.
} 
tioned in three sources were reviewed by two knowledgeable informants; five of these were added to the master list, resulting in 74 target researchers.

Finally, citedness in the SciSearch and Social SciSearch databases for the period from 1974 through July 1994 was examined. ${ }^{4}$ Duplicate postings between the two databases were removed. The number of citations retrieved may substantially overstate citedness, particularly in common names and in individuals using a single initial. However, when co-citation patterns were examined (see below ), retrieval was almost entirely restricted to targeted researchers.

Table 1 presents the names of the researchers selected for the study, along with their three-letter codes.

\section{Questionnaire}

A questionnaire was developed and pretested, then revised based on a review by several knowledgeable informants involved with dyslexia research. Components included a sociometric roster, questions on the nature of problem area(s) of current research activity, service on editorial boards, and basic biographical data. A curriculum vitae (C.V.) was requested to substitute for much of the questionnaire if the respondent so chose. Survey data were interpreted in conjunction with, and cross-checked against, published biographical sources (e.g., Who's Who), lists of editorial boards, and a search of the CRISP database, a database of research projects funded by the National Institutes of Health (NIH).

\section{Efforts to Encourage Survey Returns, and Response Rate}

Several approaches were used to maximize the return rate, including phone calls to all 58 researchers in North

\footnotetext{
${ }^{4}$ Total citedness ranged from 2 to more than 12,000 mentions of each of the 74 researchers. The two names receiving fewer than 110 references were known to be quite active in the informal communication structure. Consequently, all 74 names were retained in the interest of completeness.

The SciSearch and Social SciSearch databases are far from comprehensive, so that inaccuracies include under-reporting the impact of researchers who are cited in sources not covered by the databases, as well as apparent over-reporting of researchers with common names. A quick check of the 101 journals on which network researchers report having served on editorial boards showed that in 1989 only $53 \%$ of the journals were indexed by ISI. Many, if not most, of those journals not covered by ISI also were not indexed by MEDLINE. This suggests that these titles are probably not among the most influential in scholarly and scientific communication. However, as suggested above, members of an emerging network tend to publish in less easily accessed journals. Consequently, one would expect that ISI citations under-represent researchers in the emerging perspective, and over-represent those in the more established perspective. Thus, the deficiencies in coverage of the ISI databases, though unfortunate, should tend to emphasize the differences between the two perspectives rather than obscure them.

An equally serious problem in coverage is the important role played by edited books and conference proceedings in this problem area. It is hoped that the acknowledged deficiencies of co-citation analysis using ISI data will be partly offset by the use of the additional strategies used in the triangulation strategy.
}

America ( of the total of 73 living target researchers) prior to the first mailing of the survey, and the inclusion of postage, U.S. currency, or international postal orders sufficient to cover the cost of enclosing a C.V. Subsequent contacts included a follow-up letter with postage 2 months later, additional telephone contacts to non-respondents in North America, second copies of the survey upon request, and reminder postcards. Second copies of the survey were sent to all international non-respondents outside North America and to those who could not be reached by telephone, accompanied by personalized cover letters that mentioned ongoing results (e.g., response rate, relative citedness within the field). Final reminder postcards were mailed 6 months after the initial survey.

Seven individuals did not respond due to incorrect address, illness, or not being actively involved in dyslexia research. Non-respondents did not differ significantly (by t-tests) from respondents in citizenship, mean co-citedness at T3, number of NIH grants, or co-citation group membership at T3. There was a significant difference in professional age (years since doctoral degree) between respondents and those non-respondents for whom degree date was available. However, it is likely that older, betterknown respondents are more apt to have entries in biographical sources than are younger researchers, so it is not clear whether this relationship would hold for all nonrespondents if data on degree data were more complete.

There were 55 complete or partial surveys, and an overlapping 54 sociometric rosters. Half of all researchers returned curriculum vitae, while information from external biographical sources was available for an overlapping 25 individuals. Available response data thus varied substantially from measure to measure.

\section{Coding of Self-Reported Problem Areas}

On the survey, researchers were asked to report up to three current problem areas along with a more specific research focus in an attempt to assess the diversity and range of topics currently of interest to the problem network. These included a wide range of topics including " "aiding disabled readers," "brain reserve capacity," "consciousness," "hemispheric specialization," "phonological awareness," "reading \& reading disability," and "visual processing." Given the prevalence of a psychology background in the problem network, and the nature of reported responses, a scheme for coding the problem areas was adapted from the Content Classification System used by the PsycINFO database (Walker, 1994, p. $\mathrm{xxi}$ ), as a method of verifying labels attached to blocks. ${ }^{5}$

\footnotetext{
${ }^{5}$ Due to difficulties in differentiating between topics pertaining to sensory or cognitive processes (code group $2300+$ ) and those pertaining to neuroscience (code group 2500+), the two concepts were grouped together into a neuropsychology code. Topics which fell logically into more than one category were coded as present in both. For example, an interest in the neurobehavioral basis of dyslexia was coded as both "Disabilities" and "Neuropsychology." For consistency across cases, mention of some aspect of reading was coded under the "Education/
} 
TABLE 1. Codes and names of dyslexia researchers included in the study.*

\begin{tabular}{|c|c|c|c|c|c|}
\hline No. & Code & Name & No. & Code & Name \\
\hline 1 & Bak & Bakker & 38 & Lun & Lundberg \\
\hline 2 & Ben & Benton & 39 & Lyo & Lyon \\
\hline 3 & Bla & Blachman & 40 & Maf & Manis, F \\
\hline 4 & Bod & Boder & 41 & Mav & Mann, V \\
\hline 5 & Bos & Bos & 42 & Mar & Martin \\
\hline 6 & Bra & Brady & 43 & $\mathrm{McC}$ & McConkie \\
\hline 7 & Bre & Breitmeyer & 44 & $\mathrm{McK}$ & McKinney \\
\hline 8 & Bry & Bryant & 45 & Mor & Morrison \\
\hline 9 & Chf & Chalfant & 46 & Ols & Olson \\
\hline 10 & Chl & Chall & 47 & Pav & Pavlidis \\
\hline 11 & $\mathrm{DeF}$ & DeFries & 48 & Pen & Pennington \\
\hline 12 & Den & Denckla & 49 & Pir & Pirozzolo \\
\hline 13 & DiL & DiLolla & 50 & Ray & Rayner \\
\hline 14 & Doe & Doehring & 51 & Rou & Rourke \\
\hline 15 & Dua & Duane & 52 & Rum & Rumsey \\
\hline 16 & Duf & Duffy & 53 & Rut & Rutter \\
\hline 17 & Ede & Eden & 54 & Sat & Satz \\
\hline 18 & Fis & Fisher & 55 & Sei & Seidenberg \\
\hline 19 & Fle & Fletcher & 56 & Shd & Shankweiler, D \\
\hline 20 & $\mathrm{Gal}$ & Galaburda & 57 & Shb & Shaywitz, B \\
\hline 21 & Gib & Gibson & 58 & Shs & Shaywitz, S \\
\hline 22 & Hal & Hallahan & 59 & She & Sherman \\
\hline 23 & Ham & Hammill & 60 & Sie & Siegel \\
\hline 24 & Hug & Hugdahl & 61 & Smi & Smith \\
\hline 25 & Hyn & Hynd & 62 & Stg & Stanley, G \\
\hline 26 & Joh & Johnson & 63 & Stk & Stanovich, K \\
\hline 27 & Jor & Jorm & 64 & Ste & Stein \\
\hline 28 & $\mathrm{Kvl}$ & Kavale & 65 & Tal & Tallal \\
\hline 29 & Kvn & Kavanagh & 66 & Tor & Torgesen \\
\hline 30 & Kin & Kinsbourne & 67 & Udd & Udden \\
\hline 31 & Laj & Larsen, J & 68 & Vel & Vellutino \\
\hline 32 & Las & Larsen, $\mathrm{S}$ & 69 & Vog & Vogel \\
\hline 33 & Leo & Leong & 70 & Von & Von Euler \\
\hline 34 & Lia & Liberman, A & 71 & Wim & Williams, M \\
\hline 35 & Lii & Liberman, I & 72 & Wid & Willows, D \\
\hline 36 & Liv & Livingstone & 73 & Won & Wong \\
\hline 37 & Lov & Lovegrove & 74 & Woo & Wood \\
\hline
\end{tabular}

* Note: Names are generally coded by the first three letters of the researcher's last name. In cases where this would lead to duplicate codes, the third letter reflects either the researcher's first name (e.g., Laj $=$ J. Larsen) or a subsequent letter in the researcher's last name (e.g., Kvl $=$ Kavale).

Table 2 summarizes some relevant characteristics of the respondents.

\section{Network Analysis Procedures}

The co-citation data and self-reported who-to-whom communication data were analyzed using a variety of frequently used network analysis techniques, including conversion of the raw data matrix to a correlation matrix,

Learning" code, although a research interest in reading could conceivably be grouped under neuropsychology or some other code. Where additional detail was provided (e.g., Language Processes in Reading), more than one code was assigned (e.g., Language, Education/Learning ). In addition, in view of the focus of the study on alternative perspectives, a separate category indicated whether researchers had any interest in some aspect of vision, eye movements, or a visual processing deficit. This was considered a subset of the Neuropsychology code. clustering, and multi-dimensional scaling (McCain, 1990b).

\section{Co-Citation Analysis}

Author co-citation analysis maps linkages among documents based on their joint citation by subsequent researchers (e.g., see White, 1990; White \& Griffith, 1981). The pattern of co-citation is assumed to reflect the intellectual organization of the scholarly community, and the value placed on previous work by later authors. Author co-citation analysis is based on sets of documents the body of works of an author, rather than single articles or books and thus its results tend to be fairly stable over time, unless they indicate a major shift in research activity or scholarly orientation within the field (McCain, 1990b). Since author co-citation analysis uses the entire relevant 
TABLE 2. Characteristics of respondents.

\begin{tabular}{lccr}
\hline \multicolumn{1}{c}{ Variable } & $N$ & Mean & SD \\
\hline Dr. date & 62 & 1968 & 11.9 \\
MA/MS date & 35 & 1965 & 9.4 \\
No. affiliations & 60 & 4.2 & 2.8 \\
\hline \multicolumn{1}{c}{ Variable } & $N$ & $\%$ \\
\hline Type of degree & & \\
Ph.D. & 50 & 67.6 \\
M.D. & 12 & 16.2 \\
D.Ed. & 5 & 6.8 \\
Missing & 7 & 9.5 \\
Discipline & & \\
Psychology & 34 & 45.9 \\
Medicine & 12 & 16.2 \\
Psychology, clinical & 6 & 8.1 \\
Education & 6 & 8.1 \\
Speech/hearing/communication & 3 & 4.1 \\
Biology, specialized & 2 & 2.7 \\
Missing & 11 & 14.9 \\
Problem area & & \\
Disabilities & 65 & 89.0 \\
Neuropsychology & 61 & 67.0 \\
Education/learning & 59 & 41.0 \\
Language & 62 & 32.0 \\
Vision interest & 57 & 28.0 \\
Developmental psychology & 58 & \\
Social issues & 58 & \\
\hline
\end{tabular}

database resources of the Institute for Scientific Information (ISI), it tracks perceptions beyond a limited number of knowledgeable informants, bibliographies, or other sources known to a single investigator. Citation and cocitation analysis have been used to test for possible convergence between different research traditions (Borgman \& Rice, 1992; Cottrill, Rogers, \& Mills, 1989; Rogers \& Cottrill, 1990) and to trace changes in a field over time (e.g., McCain, 1984, 1986; Paisley, 1990).

\section{Network Identification, Membership, and Positions}

Actors (here, dyslexia researchers) are assigned to separate subgroups, or positions, because of the similarity (or "structural equivalence") of their ties (here, co-citations or reported communication) with all others, as distinct from the mere presence of links between them (Knoke \& Kuklinski, 1982, p. 19; Wasserman \& Faust, 1994, p. 348).

The present study used the CONCOR algorithm (CONvergence of iterated CORrelations) to partition individuals into blocks or positions (Breiger, Boorman, \& Arabie, 1975). In CONCOR, repeated calculation of correlations between rows and/or columns of a matrix is used to produce a correlation matrix consisting entirely of $+1 \mathrm{~s}$ and $-1 \mathrm{~s}$. These correlations are then partitioned and simplified into two subsets in which correlations among items in one subset are equal to +1 , and correlations with items in the other subset are equal to -1 . The procedure thus maximizes the differences between the actors in the two blocks or clusters. A block then is a position occupied by structurally equivalent actors. CONCOR may be run to divide the subsets into additional partitions, a top-down hierarchical clustering approach (Breiger, 1976, p. 120). ${ }^{6}$ It has been used to study network structure in other scientific problem areas (Breiger, 1976; Mullins, Hargens, Hecht, \& Kick, 1977; White, Boorman, \& Breiger, 1976), and to examine the influence of network structure on the diffusion of an innovation among physicians (Anderson, Jay, Schweer, Anderson, \& Kassing, 1987).

CONCOR was used to partition the study sample using co-citation data for the three time periods (T1, T2, T3), and using who-to-whom sociometric data collected on the questionnaire (T3). Results at the two block level will be presented in order to examine major trends in the development of alternative groups and the ties within and between these clusters. In some analyses, each block will be further split into two sub-blocks (1A and 1B;2A and 2B) to examine more subtle distinctions within the clusters.

\section{Results}

\subsection{RQ1: Formal (Co-Citation) Networks}

HIa. Neuroscience-Vision and Phonological Dyslexia Researchers Are Associated with Separate Co-Citation Blocks Associated with Time Periods T1-T2-T3.

\section{Co-Citation Network, T2 and T3}

The researchers in both the co-citation and who-towhom networks were partitioned into two groups which generally can be labeled as Neuroscience-vision, or simply Neuroscience (Emerging Hybrid), or Phonological (Established). Support for these labels at T2 and T3 will be presented first, due to certain complexities in the T1 results.

All members (100\%) of the co-citation block labeled Neuroscience at T3 reported a current research interest in neuropsychology and related problem areas. This compares with only $40 \%$ of researchers in the Phonological block at that time period (t-test, $p<.001$ ). Those in the Phonological block at T3 were correspondingly more likely to be interested in topics related to language problems $(40 \%$ compared to $20 \%, p<.05)$ and education/ learning ( $60 \%$ compared to $20 \%, p<.005$ ). There was no significant difference between blocks in members'

\footnotetext{
${ }^{6}$ Although CONCOR is not without criticism (Rice \& Richards, 1985 , p. 127; Wasserman \& Faust, 1994, p. 380), it is one of the most widely used algorithms (Knoke \& Kuklinski, 1982, p. 69), and is appropriate for comparing and contrasting formal and informal networks, as in the present study. In addition, the procedure is relatively easy to understand.
} 
self-reported involvement in disabilities research. Although differences are somewhat less pronounced at T2 for a focus on neuropsychology or education/learning, they are still significant for all reported areas of interest. These differences remained significant for the T3 (informal) who-to-whom network only for choice of neuropsychology as a problem area (Neuroscience $=90 \%$, Phonological $=50 \%, p<.001)$.

Similar differences exist between blocks for educational background and involvement on editorial boards concerned with learning disabilities, reported for T3, the period at which the clearest differences between blocks emerge. Neuroscience members are significantly more likely to hold the M.D. degree (36\% compared to $9 \%, p$ $<.01)$ and/or to have a background in specialized areas of biology ( $28 \%$ compared to $0 \%, p<.001$ ). Members of the Phonological block are more likely to have a background in education (32\% compared to $8 \%, p<.05$ ) and to have been active on the editorial boards of two of the primary journals concerned with learning disabilities: Journal of Learning Disabilities (JLD) (51\% compared to $21 \%, p<.01$ ) and Learning Disabilities Quarterly ( $L D Q)$ ( $31 \%$ compared to $4 \%, p<.01)$. The publisher of $J L D$ also is grouped with the Phonological block.

Overall, the editorial activities of the researchers in the study group are distinguished by their tremendous diversity. From 55 respondents, more than 100 different journals were listed, ranging from Neurosurgery to School Psychology Review, with $J L D$ and $L D Q$ the most frequently mentioned. Patterns of indexing and subject orientation suggest that presence on the editorial boards of $J L D$ and/or $L D Q$ may be interpreted as an additional indicator of a phonological, as compared to a neuroscience, research focus. In summary, block members differ significantly from one another in their educational backgrounds, choice of self-identified research interest(s), and editorial board activity, in a manner consistent with and characteristic of the labels attached to each block.

Figure 1 shows the two-dimensional plot (using principal components factor loadings) of co-citation data for T3, with block structure superimposed upon it. (Note that the two-dimensional factor plots explain no more than $37 \%$ of the variance in any time period, and that a solution in three or more dimensions probably is required for greater accuracy.) The two-dimensional plot at T2 (not shown) is similar, although block membership is more mixed.

Individuals who are located closely together are perceived by citing (and non-citing) authors in a similar way. Individuals closest to the center of the plots have the lowest co-citation levels. These include younger researchers, migrants who may not have published extensively on topics related to dyslexia at the time period in question, those who are no longer active in the area, and those who are active in the informal but not the formal dyslexia network. Those furthest to the right on the plot are the more established researchers in the field. Among the phonological group at both T2 and T3 are such highly cited individuals as Stanovich, Isabelle Liberman, and Torgesen, all of whose work is firmly in the phonological tradition. Those consistently grouped in the neuroscience block include Pennington, Smith, and Stein, who have published on such topics as genetics (Pennington and Smith) and visual processing (Stein). Separate co-citation structures reflecting the alternative intellectual perspectives emerge most clearly at $\mathrm{T} 3$.

\section{Co-Citation Network, T1}

The network structure at $\mathrm{T} 1$ poses a somewhat more complicated picture than during later periods. The fact that some of these otherwise opposed individuals (e.g., Breitmeyer \& Ganz, 1976; Lovegrove et al., 1986; as opposed to Stanovich, 1979) are partitioned into the same block at T1 is likely due to the joint positive and negative citing of references reflecting both perspectives in articles published between 1976 and 1987, such as the series of papers exchanged between Fletcher and Satz (1979a, 1979b) and Vellutino et al. (1977; Vellutino, 1979). This situation appears to match Mulkay's description of phase one in the development of a problem area, which "can be seen as a 'negotiation' between researchers with initially different views about the theories, methods and problems appropriate to a problem area of common interest'" (Mulkay et al., 1975, p. 195). By T3, this period of negotiation and discussion appears to have ended.

The differences between blocks at the two-block level at $\mathrm{T} 1$ are significant for neuropsychology research interest ( mixed neuroscience-vision block, 85\% compared to 59\% for mixed phonological block, $p<.05$ ), but not for language or education/learning focus. This reflects the extremely mixed nature of block membership at this early point in time. Members of the neuroscience block, which might more appropriately be termed the neurosciencevision block at this time period (T1), also are significantly more interested in topics related to vision such as eye movements, visual processing, and visual perception (56\% compared to $15 \%, p<.005$ ). Differences between blocks in other areas of interest (developmental psychology, social processes, disabilities) were not significant.

In addition, $\mathrm{T} 1$ partitions exhibit a center-periphery pattern at the two-block level quite unlike that in later years. Overall, members of the insider block reflect a more phonological perspective than those in the outsider block. However, within the insider block are sub-blocks which can be characterized as primarily neuroscientific and primarily phonological in orientation; within the outsider block are those with a neuroscience-vision orientation and those who are not co-cited at all. Figure 2 illustrates the relative dominance of the mixed phonological block at T1. Nearly all neuroscience block members are located relatively centrally and to the left of phonological block members, reflecting their lower co-citation counts and emerging status. The mixed nature of the primarily phono- 


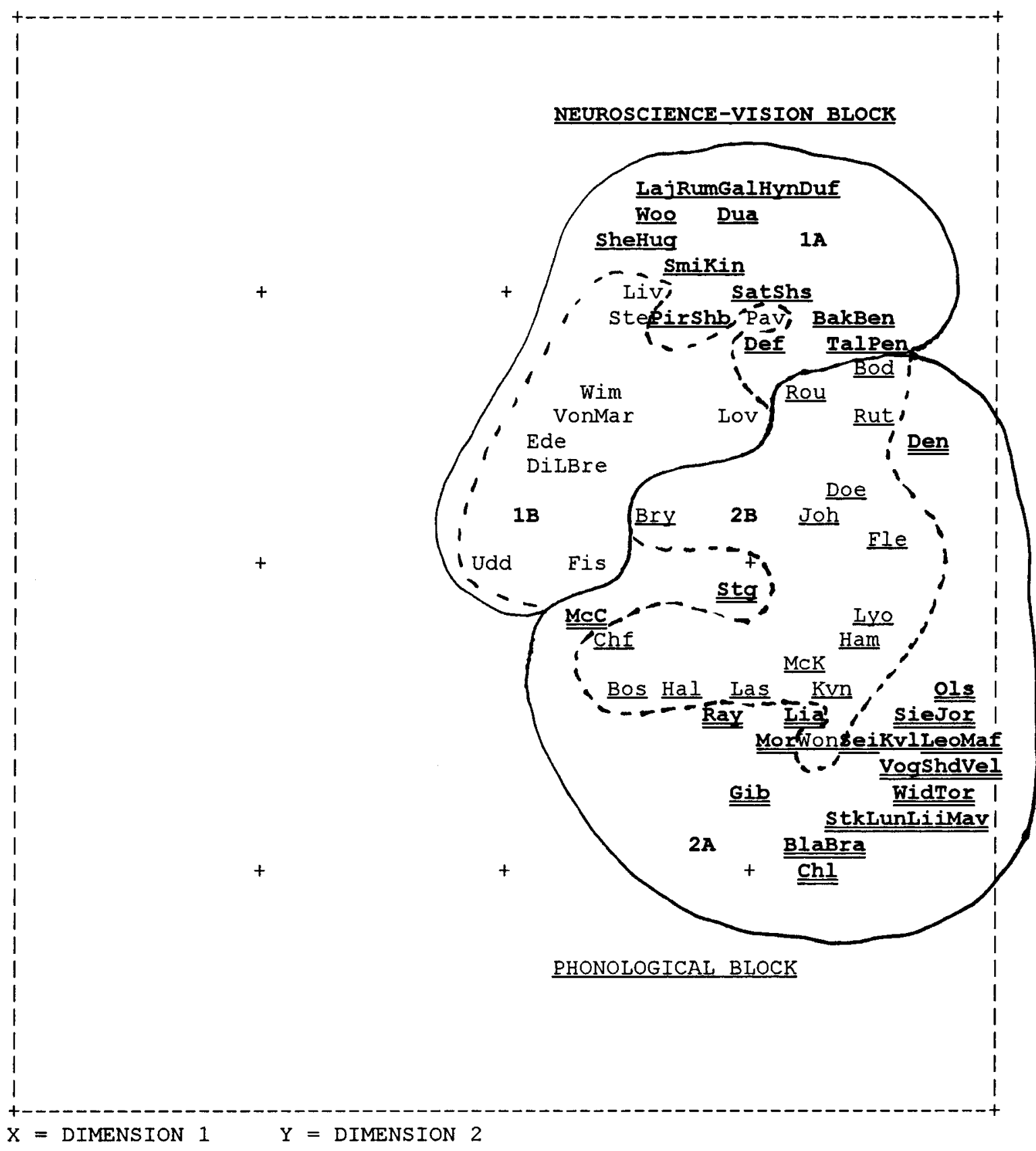

Bold, underlined=Neuroscience Sub-block $1 \mathrm{~A}$

Regular font=Neuroscience-vision Sub-block $1 \mathrm{~B}$

Bold, double-underlined=Phonological sub-block $2 \mathrm{~A}$ Regular font, underlined= Phonological sub-block $2 \mathrm{~B}$

FIG. 1. Plot of researchers using unrotated factor loadings at time three (1988-1993).

logical block at this time period is suggested by the presence of Bakker, Benton, Galaburda, and Tallal, whose published work is closely identified with a neuroscientific focus (e.g., Bakker, Moerland, \& Goekoop-Hoetkens, 1981; Benton, 1975; Galaburda, 1989; Tallal et al., 1993). All of these researchers are partitioned in the neuroscience block by $\mathrm{T} 3$.

\section{Differences across Co-Citation Blocks, T1 and T3}

H1b. In the Co-Citation Network Structure, Phonological Dyslexia Researchers Are More Highly Co-Cited with Other Network Members Than Are Neuroscience-Vision esearchers (T1, T3). 
HIc. In the social network structure, phonological dyslexia researchers are more highly co-cited with other network members than are neuroscience-vision researchers (T3). Support for these hypotheses was mixed, depending on the time period, the network examined (formal vs. informal) and the level of partitioning, as discussed under RQ3. However, as hypothesized, members of the emerging neuroscience-vision block-based both on co-citation and informal communication networkswere significantly less highly co-cited than were members of the established phonological block at T1 (.5 compared to $2.3, p<.005)$. In addition, consistent with an emerging group of researchers, they received their doctoral degrees at a significantly later date (1974 compared to $1966, p$ $<.01)$.

\subsection{RQ2: Characteristics of Co-Citation Networks over Time}

H2a. The Co-Citation Blocks of Neuroscience-Vision and Phonological Dyslexia Researchers Become Less Separate over Time (T1-T2-T3).

H2b. The degree of intellectual linkage (mean co-citation strength) in the problem area increases over time $(T 1-T 2-T 3)$. The mean strength of co-citation links in the problem area overall, as well as in the most highly co-cited block, at each time period increased steadily over the 17-year period. The mean co-citation strength, or density of links, is defined as the number of actual links divided by the number of possible links. The overall mean strength at $\mathrm{T} 1$ was only 1.85 , had increased to 4.91 in $\mathrm{T} 2$, and risen to 6.86 in T3. This suggests that the problem area as a whole was becoming more visible within the larger scientific community, since co-citedness is dependent on the citing patterns of scientists throughout the literature, as indexed by the Institute for Scientific Information (ISI).

The pattern of rising co-citation levels also suggests that researchers within specific blocks were becoming more closely connected. The mean strength of the most highly co-cited block at T1 (phonological) was 3.39. At $\mathrm{T} 2$, the mixed neuroscience block had become the most strongly linked $($ mean $=7.58)$. By T3, the phonological block was again most strongly linked, with a mean of 10.79. Both patterns (rising mean strength of links overall and within blocks) are consistent with an increase in the overall number of articles produced, a rise in the citedness of key articles, and growing consensus, as proposed in Mulkay and co-workers' model of growth in a research area (1975, p. 192, 196-197). The patterns suggest that the problem area is entering the "unification" phase of scholarly change. Even those individuals who were initially outside the problem area had largely become integrated into the wider formal network by $\mathrm{T} 3$.

However, this did not necessarily mean that the cocitation blocks became less separate over time. For exam- ple, at $\mathrm{T} 1$, the grand mean (over the entire $74 \times 74$ cocitation matrix) was 1.85 . Only the mean of the phonological block (3.39) for T1 exceeds the grand mean. Between 1976-1981, the neuroscience-vision block is basically invisible: Its members are not co-cited with others (mean strength $=.36$ ), nor are they much co-cited with others within their block (.66). In both T2 and T3, the relationship between blocks is reflexive: Block members are cocited with each other but largely not with those in the other block, relative to the grand mean of the network as a whole. Thus, the only sense in which the blocks became less separate over time is in terms of the increasing integration of the outsiders into the network as a whole.

The four-block level of analysis replicates this pattern, but provides some additional levels of detail. For each time period, Table 3 presents not only the sub-block densities (mean co-citation strength of each sub-block), but also a reduced presentation of the data called an image matrix. In each image matrix, a " 1 " is assigned if the link density is greater than the grand mean, and a " 0 ", if the density is less than the grand mean, thus making the relationship among sub-blocks easier to discern. Those cells with a " 0 " are essentially unconnected to the larger network structure.

As indicated in the image matrices in Table 3, the two inner sub-blocks (2A and 2B) at $\mathrm{T} 1$ (the outsiders and neuroscience-vision researchers) are basically outside the network in terms of co-citedness. (Note that block locations at $\mathrm{T} 1$ are the reverse of those at other time periods simply due to data order; this has no substantive significance.) They are virtually invisible in terms of the larger group structure, as indicated by the " 0 "' $s$ in the image matrix. By T2, the mixed neuroscience sub-block (1A) has the highest sub-block density, although a group of neuroscience outsiders (sub-block 1B) remains relatively uncited. This sub-block includes some, but not all, of those individuals who were uncited at Time 1 .

By T3, all sub-blocks are co-cited with themselves at least as often as the mean for the network as a whole, as indicated by the string of " 1 "'s across the diagonal. The pattern is once again reflexive. However, the neuroscience-vision sub-block (1B) is much less highly co-cited than its companion neuroscience sub-block (1A), both with itself and with other sub-blocks. Phonological subblock $2 \mathrm{~A}$ is by far the most highly co-cited within the network, with a mean co-citation density nearly three times that of the network mean. Although less than the mean, the density of co-citations between and among the first three sub-blocks is above 5.09, suggesting that these sub-blocks are more integrated into the intellectual network than are members of the neuroscience-vision subblock (1B). Once again, the data point to the relative isolation of those most closely identified with the visionrelated aspects of dyslexia research.

Consideration of the figures discussed earlier with the image matrices in hand may provide some additional understanding of the connections between and among the 


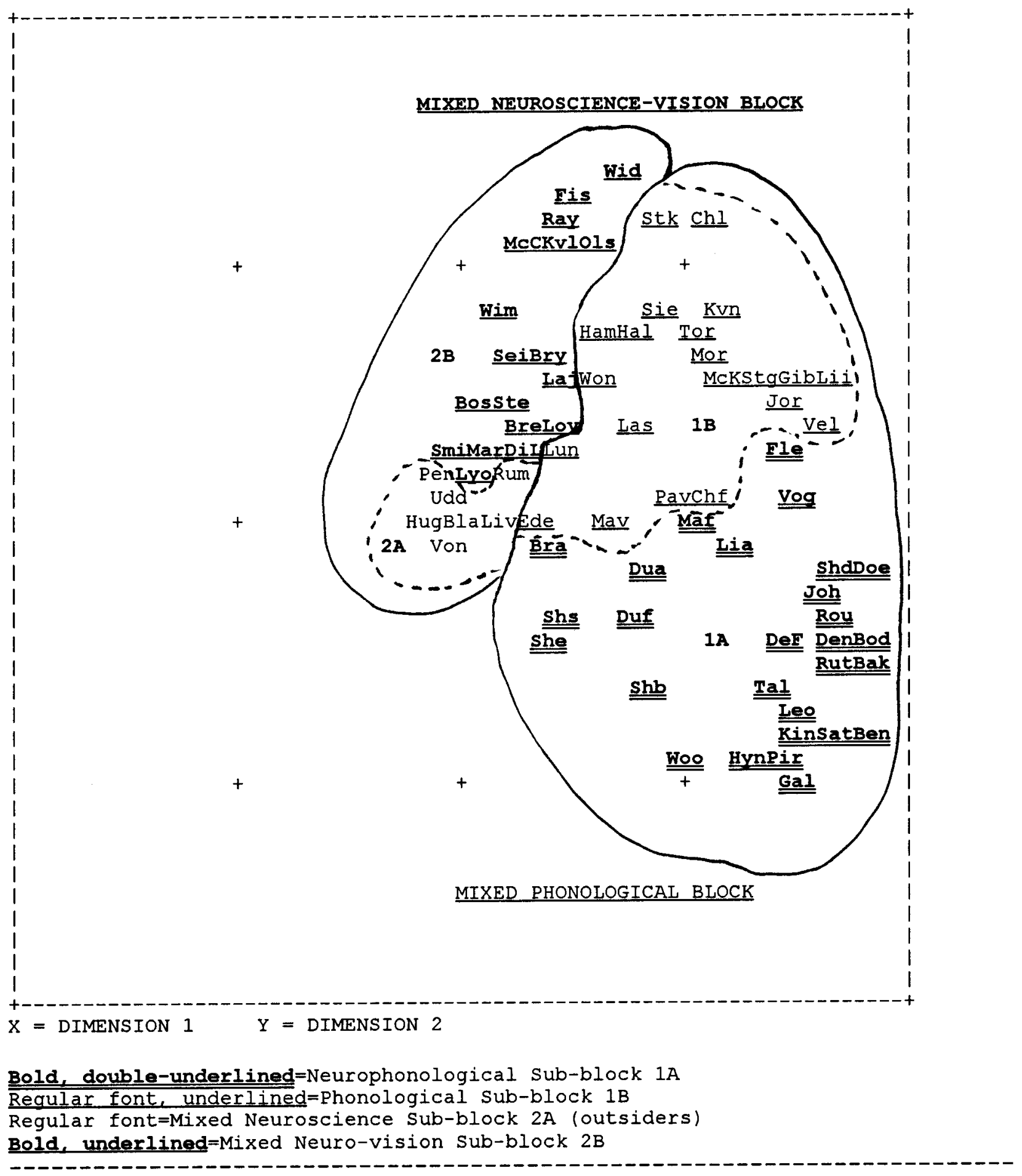

FIG. 2. Plot of researchers using unrotated factor loadings at time one (1976-1981).

blocks over time. For example, at T1 (Fig. 2), the small mixed neuroscience cluster $(2 \mathrm{~A} / 2 \mathrm{~B})$ is represented by the " 0 "'s in the corresponding image matrix (Table 3 ), suggesting its outsider status. By T3 (Fig. 1), each subblock has a distinct reflexive character, with higher co- citation densities corresponding to a more closely grouped two-dimensional display for a particular sub-block. Thus the alternative representations of the data complement and augment one another.

In summary, the individuals within the network were 
TABLE 3. Densities and image matrices, 4-block level, times 1, 2, and 3.*

\begin{tabular}{|c|c|c|c|c|c|c|c|c|}
\hline \multicolumn{5}{|c|}{$\mathrm{T} 1$ block densities } & \multicolumn{4}{|c|}{ T1 image matrix } \\
\hline Alpha $=1.85$ & $\begin{array}{c}\text { Neuro-phon. } \\
\text { 1A }\end{array}$ & $\begin{array}{l}\text { Neuroscience } 2 \mathrm{~A} \\
\text { (outsiders) }\end{array}$ & $\begin{array}{l}\text { Neuro-vision } \\
\text { 2B }\end{array}$ & $\begin{array}{c}\text { Phonological } \\
\text { 1B }\end{array}$ & $\begin{array}{l}\mathrm{PH} \\
1 \mathrm{~A}\end{array}$ & $\begin{array}{l}\text { NS } \\
2 \mathrm{~A}\end{array}$ & $\begin{array}{l}\mathrm{NV} \\
2 \mathrm{~B}\end{array}$ & $\begin{array}{l}\mathrm{PH} \\
1 \mathrm{~B}\end{array}$ \\
\hline Neuro-phono sub-block 1A & 5.35 & .00 & 0.34 & 2.11 & 1 & 0 & 0 & 1 \\
\hline $\begin{array}{l}\text { Neuroscience sub-block } 2 \mathrm{~A} \\
\text { (outsiders) }\end{array}$ & .00 & .00 & 0.01 & .01 & 0 & 0 & 0 & 0 \\
\hline Neuro-vision sub-block 2B & .34 & .01 & 1.28 & .72 & 0 & 0 & 0 & 0 \\
\hline Phonological sub-block 1B & 2.11 & .01 & 0.72 & 3.47 & 1 & 0 & 0 & 1 \\
\hline \multirow{2}{*}{\multicolumn{5}{|c|}{$\mathrm{T} 2$ block densities }} & \multicolumn{4}{|c|}{$\mathrm{T} 2$ image matrix } \\
\hline & & & & & & & & \\
\hline Alpha $=4.91$ & $\begin{array}{l}\text { Mixed NS } \\
1 \mathrm{~A}\end{array}$ & $\begin{array}{l}\text { Mixed Phon } \\
2 \mathrm{~A}\end{array}$ & $\begin{array}{l}\text { Mixed Phon } \\
\text { 2B }\end{array}$ & $\begin{array}{l}\text { Mixed NS 1B } \\
\text { (outsiders) }\end{array}$ & $\begin{array}{l}\mathrm{NS} \\
1 \mathrm{~A}\end{array}$ & $\begin{array}{l}\mathrm{PH} \\
2 \mathrm{~A}\end{array}$ & $\begin{array}{l}\mathrm{PH} \\
2 \mathrm{~B}\end{array}$ & $\begin{array}{l}\text { NS } \\
1 \mathrm{~B}\end{array}$ \\
\hline Mixed neuro sub-block 1A & 11.84 & 4.14 & 3.33 & .98 & 1 & 0 & 0 & 0 \\
\hline $\begin{array}{l}\text { Mixed phonological sub- } \\
\text { block } 2 \mathrm{~A}\end{array}$ & 4.14 & 7.69 & 2.97 & .13 & 0 & 1 & 0 & 0 \\
\hline $\begin{array}{l}\text { Mixed phonological sub- } \\
\text { block 2B }\end{array}$ & 3.33 & 2.97 & 11.33 & .32 & 0 & 0 & 1 & 0 \\
\hline $\begin{array}{l}\text { Mixed neuroscience sub- } \\
\text { block 1B (outsiders) }\end{array}$ & .98 & .13 & .32 & 1.86 & 0 & 0 & 0 & 0 \\
\hline \multirow{2}{*}{\multicolumn{5}{|c|}{ T3 block densities }} & \multicolumn{4}{|c|}{ T3 image matrix } \\
\hline & & & & & & & & \\
\hline Alpha $=6.86$ & NS $1 \mathrm{~A}$ & Phon $2 \mathrm{~A}$ & Phon 2B & NS-vis $1 \mathrm{~B}$ & $1 \mathrm{~A}$ & $2 \mathrm{~A}$ & $2 \mathrm{~B}$ & $1 \mathrm{~B}$ \\
\hline Neuroscience sub-block 1A & 12.41 & 5.26 & 5.09 & 2.95 & 1 & 0 & 0 & 0 \\
\hline Phonological sub-block 2A & 5.26 & 18.69 & 6.27 & 2.90 & 0 & 1 & 0 & 0 \\
\hline Phonological sub-block 2B & 5.09 & 6.27 & 7.48 & 1.04 & 0 & 0 & 1 & 0 \\
\hline $\begin{array}{l}\text { Neuroscience-vision sub- } \\
\text { block 1B }\end{array}$ & 2.95 & 2.90 & 1.04 & 7.32 & 0 & 0 & 0 & 1 \\
\hline
\end{tabular}

* Density = actual links/possible links; Alpha = grand mean for the matrix as a whole; " 1 ", = density of links from position $\left(B_{i}\right)$ to position $\left(B_{j}\right)>$ alpha; " 0 " = density of links from position $\left(B_{i}\right)$ to position $\left(B_{j}\right)<$ alpha (where ${ }_{i}$ and ${ }_{j}$ equal the rows and columns). The image matrix is a reduced presentation of the data which shows ties between positions. A ' 0 " in a position indicates a relative lack of ties between sub-blocks; and " 1 " indicates a greater than average density of ties.

co-cited with one another in increasing numbers over time, indicating stronger intellectual linkages in the problem area overall, in support of Hypothesis 2b. However, the co-citation blocks showed no signs of becoming less separate over the three time periods, so Hypothesis 2a must be rejected.

\subsection{RQ3: Informal (Communication) Networks: Convergence or Divergence?}

H3. The Social Communication Network in the Problem Area at T3 Includes Blocks of Individuals from the Neuroscience-Vision Dyslexia Co-Citation Networks (from T1 and T3) and from the Phonological Dyslexia Co-Citation Networks (from T1 and T3). Table 4 presents the names of researchers partitioned into two alternative blocks at the three time periods, incorporating the co-citation and social network data. Names in boldface type reflect the researchers in the neuroscience co-citation block at T3; those without boldface indicate membership in the phonological co-citation block at T3. By following the boldface type for different time periods (or types of network), one can trace individuals' movement within and between various blocks, and overlap between the formal (co-citation) and informal (social) networks at T3.

For example, more than two-thirds of those grouped in the neuroscience co-citation block at T3 also are partitioned in the neuroscience social block at T3. Individuals consistently grouped together in the neuroscience block in all analyses include Hugdahl, J. Larsen, Livingstone, Rumsey, Smith, Stein, and Udden. A number of these researchers do not consider themselves part of the dyslexia research network but are nonetheless mentioned by other researchers as being people with whom they communicate in matters pertaining to dyslexia.

The neuroscience social (who-to-whom) block includes researchers who regularly publish on topics related to vision processing, and who are co-cited with the neuro- 
TABLE 4. Two-block structure, co-citation networds T1, T2, and T3, and who-to-whom network (column data) T3.*

\begin{tabular}{|c|c|c|}
\hline Time per./network & Neuroscience block (block 1 except at T1) & Phonological block (block 2 except at T1) \\
\hline \multicolumn{3}{|l|}{ Time 1} \\
\hline Co-citation (blocks are switched) & $\begin{array}{l}\text { Bla Bos Bre Bry DiL Fis Hug Kvl Laj Liv } \\
\text { Lov Lyo Mar McC Ols Pen Ray Rum } \\
\text { Sei Smi Ste Udd Von Wid Wim }(n=25)\end{array}$ & $\begin{array}{l}\text { Bak Ben Bod Bra Chf Chl DeF Den Doe Dua } \\
\text { Duf Ede Fle Gal Gib Hal Ham Hyn Joh Jor } \\
\text { Kvn Kin Las Leo Lia Lii Lun Maf Mav McK } \\
\text { Mor Pav Pir Rou Rut Sat Shb Snd She Shs Sie } \\
\text { Stg Stk Tal Tor Vel Vog Won Woo }(n=49)\end{array}$ \\
\hline \multicolumn{3}{|l|}{ Time 2} \\
\hline Co-citation & $\begin{array}{l}\text { Bak Ben Bod Bry DeF Den Doe Dua Duf } \\
\text { Fle Gal Hug Hyn Joh Kin Laj Leo Liv } \\
\text { Lyo Pen Pir Rou Rum Rut Sat Shb She } \\
\text { Shs Smi Ste Udd Woo }(n=32)\end{array}$ & $\begin{array}{l}\text { Bla Bos Bra Bre Chf Chl DiL Ede Fis Gib Hal } \\
\text { Ham Jor Kvl Kvn Las Lia Lii Lov Lun Maf } \\
\text { Mar Mav McC McK Mor Ols Pav Ray Sei } \\
\text { Shd Sie Stg Stk Tal Tor Vel Vog Von Wid } \\
\text { Wim Won }(n=42)\end{array}$ \\
\hline \multicolumn{3}{|l|}{ Time 3} \\
\hline Co-citation & $\begin{array}{l}\text { Bak Ben Bre DeF DiL Dua Duf Ede Fis } \\
\text { Gal Hug Hyn Kin Laj Liv Lov Mar Pav } \\
\text { Pen Pir Rum Sat Shb She Shs Smi Ste } \\
\text { Tal Udd Von Wim Woo }(n=32)\end{array}$ & $\begin{array}{l}\text { Bla Bod Bos Bra Bry Chf Chl Den Doe Fle Gib } \\
\text { Hal Ham Joh Jor Kvl Kvn Las Leo Lia Lii Lun } \\
\text { Lyo Maf Mav McC McK Mor Ols Ray Rou } \\
\text { Rut Sei Shd Sie Stg Stk Tor Vel Vog Wid } \\
\text { Won }(n=42)\end{array}$ \\
\hline \multicolumn{3}{|l|}{ Time 3} \\
\hline Who-to-whom (columns only) & $\begin{array}{l}\text { Bak Bre DiL Duf Ede Fis Gal Hug Jor Laj } \\
\text { Lia Liv Lov Lun Maf Mar McC Ols Pav } \\
\text { Pir Ray Rum She Sei Smi Ste Stg Tal } \\
\text { Udd Von Wid Wim }(n=32)\end{array}$ & $\begin{array}{l}\text { Ben Bla Bod Bos Bra Bry Chf Chl DeF Den Doe } \\
\text { Dua Fle Gib Hal Ham Hyn Joh Kvl Kvn Kin } \\
\text { Las Leo Lii Lyo Mav McK Mor Pen Rou Rut } \\
\text { Sat Shd Shb Shs Sie Stk Tor Vel Vog Won } \\
\text { Woo }(n=42)\end{array}$ \\
\hline
\end{tabular}

\footnotetext{
T3.

* Bold font $=$ membership in the neuroscience co-citation block at T3. Medium font $=$ membership in the phonological co-citation block at
}

science-vision group at both T1 and T3. These include Breitmeyer, Lovegrove, Martin, and Williams. Researchers such as Bakker, Duffy, Galaburda, Sherman, and Tallal-individuals who are consistently partitioned with the more highly co-cited neuroscience blocks at T1 and T3are grouped in this social block as well. This suggests that at least some individuals in the vision-related group are more centrally connected than co-citation patterns would indicate. Finally, other individuals partitioned in the neuroscience social block were grouped in the phonological co-citation blocks for all time periods. These included Jorm, A. Liberman, Lundberg, Manis, McConkie, and Stanley. In support of Hypothesis 3, the social communication network is clearly composed of individuals from opposing blocks in the co-citation network structures at various times, but the patterns of co-citation and social interaction are at best only weakly associated (T1, $r=$ $.09 ; \mathrm{T} 2, r=.18$; T3, $r=.25$ ).

However, although there appears to be a slight tendency towards overall convergence of the citation and social networks, there is not necessarily evidence for convergence in the citation networks over time. Despite the existence of an integrative theory and evidence of social interaction, patterns in the co-citation data suggest that the alternative perspectives are becoming more divergent in the formal (co-citation) network structure rather than less. It is therefore possible that the relationship between the informal and formal networks reflects "a socially in- terconnected, yet cognitively more diffuse, research front' such as Lievrouw et al. described (1987, p. 246).

An alternative interpretation of the data concerns the possibility that due to the inherent delays in the publishing process, the trends revealed through co-citation analysis trail those measured using social network analysis (i.e., the measures are out of sync). If this is the case, a future co-citation analysis may better reflect the current informal network structure, and lend support to a pattern of convergence. A follow-up study tracking both the formal and informal networks will be helpful in narrowing the array of possible interpretations of the data.

Figure 3 provides a two-dimensional plot of the T3 social network space, with the more established researchers once again located the farthest to the right. In the social network structure, editorial activity is even more sharply identified with membership in a particular block than was the case in the co-citation structure. As noted previously, both the Journal of Learning Disabilities ( $J L D)$ and the Learning Disabilities Quarterly ( $L D Q)$ may be characterized as oriented more to the phonological perspective than to neuroscientific aspects of dyslexia research. Ninety percent of researchers in phonological social communication sub-block $2 \mathrm{~B}$, and $52 \%$ of those in mixed phonological sub-block $2 \mathrm{~A}$, have been members of the editorial board of $J L D$, as compared to $12 \%$ and $0 \%$, respectively, of those in neuroscience-vision subblocks $1 \mathrm{~A}$ and $1 \mathrm{~B}$. Sixty percent of phonological 2B re- 


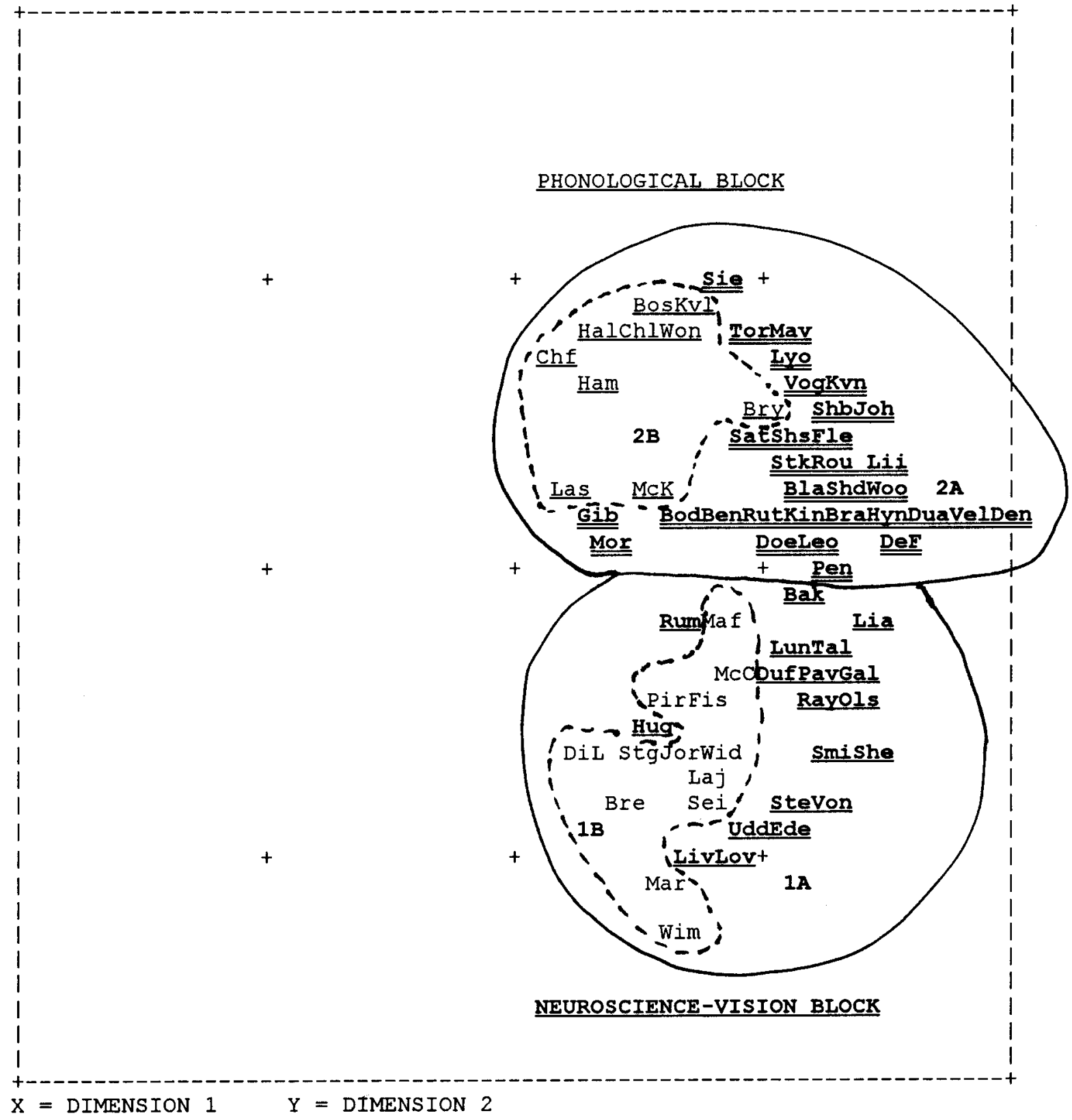

Bold, underlined=Neuroscience-vision Sub-block $1 \mathrm{~A}$

Regular font=Neuroscience-vision Sub-block 1B

Bold, double-underlined=Mixed Phonological Sub-block $2 \mathrm{~A}$

Regular font, underlined=Phonological sub-block 2B

FIG. 3. Plot of researchers using unrotated factor loadings of who-to-whom sociometric data at time three (1988-93).

searchers have served on the editorial board of $L D Q$, as compared to none for the entire neuroscience-vision block. These differences are significant $(p<.05)$ in all cases.

Although the reflexive relationship between blocks in the social network data at the two-block level also is suggestive of divergence, analysis at a finer level of detail provides additional insights. As shown in Table 5 analysis at the four-block level superimposes a center-periphery substructure on the general subject orientation of the two block split in the informal network. Some of those in subblocks $1 \mathrm{~B}$ and $2 \mathrm{~B}$ are no longer active in the field, or are 
TABLE 5. Who-whom columns block densities and who-whom image matrix.

\begin{tabular}{|c|c|c|c|c|c|c|c|c|}
\hline Alpha $=.20$ & $\begin{array}{l}\mathrm{NV} \\
1 \mathrm{~A}\end{array}$ & $\begin{array}{l}\mathrm{MP} \\
2 \mathrm{~A}\end{array}$ & $\begin{array}{l}\mathrm{PH} \\
2 \mathrm{~B}\end{array}$ & $\begin{array}{l}\text { NV } \\
1 \mathrm{~B}\end{array}$ & $\begin{array}{l}\mathrm{NV} \\
1 \mathrm{~A}\end{array}$ & $\begin{array}{l}\mathrm{MP} \\
2 \mathrm{~A}\end{array}$ & $\begin{array}{l}\mathrm{PH} \\
2 \mathrm{~B}\end{array}$ & $\begin{array}{l}\text { NV } \\
1 \mathrm{~B}\end{array}$ \\
\hline \multicolumn{9}{|l|}{ Neuroscience-vision } \\
\hline Sub-block 1A & .40 & .22 & .03 & .13 & 1 & 1 & 0 & 0 \\
\hline Mixed phonologica & & & & & & & & \\
\hline Sub-block 2A & .26 & .37 & .20 & .05 & 1 & 1 & 1 & 0 \\
\hline $\begin{array}{l}\text { Phonological Sub- } \\
\text { block 2B }\end{array}$ & .06 & .11 & .44 & .01 & 0 & 0 & 1 & 0 \\
\hline Neuroscience-visior & & & & & & & & \\
\hline Sub-block 1B & .20 & .06 & .02 & .10 & 1 & 0 & 0 & 0 \\
\hline
\end{tabular}

involved in basic research related to dyslexia but do not consider themselves dyslexia researchers.

Examination of the image matrix for the four-block level is particularly interesting (see Table 5). It reveals for the first time something other than a simple reflexive pattern. The two most central sub-blocks (neurosciencevision sub-block $1 \mathrm{~A}$ and mixed phonological sub-block 2A) communicate with each other as well as within themselves. Mixed sub-block 2A also communicates with phonological sub-block 2B (composed largely of those active on editorial boards). Sub-block 2B does not reciprocate this relationship, but has the highest density within the network, suggesting that editorial board members communicate extensively with one another, but do not reach out much to others. Mixed sub-block 2A also is significantly more highly co-cited than $2 \mathrm{~B}$, suggesting that editorial board membership in this problem area is not particularly related to one's citedness in the literature. Differences in co-citedness between other sub-blocks are not significant.

Neuroscience-vision sub-block 1B communicates with sub-block 1A, but does not communicate with itself. This seems a reasonable pattern, since as noted previously, many of these individuals are involved with basic research, have left the field, or are on its periphery. One might expect such researchers to report contacts with those who are more centrally involved with a field, although they might not have much reason to contact others in the same outsider position. Figure 4 provides yet another simplified way of representing the relationships between and among the different sub-blocks in the network, and of highlighting the central role played by neuroscience-vision sub-block $1 \mathrm{~A}$ and mixed phonological subblock 2A. This "reduced graph" shows the reflexive ties for $1 \mathrm{~A}, 2 \mathrm{~A}$, and $2 \mathrm{~B}$, the reciprocated ties between $1 \mathrm{~A}$ and $2 \mathrm{~A}$, as well as the one-way ties from $1 \mathrm{~B}$ to $1 \mathrm{~A}$ and $2 \mathrm{~A}$ to $2 \mathrm{~B}$. The isolation of sub-block $1 \mathrm{~B}$ (the neurosciencevision sub-block) is again made clear.

\section{Discussion}

\subsection{Summary of Results}

RQ1. Are Alternative Intellectual Perspectives Associated with Different Co-Citation Patterns? RQ2. Has the
Perceived Relationship Between the Perspectives Changed Over Time? RQ3. Is Convergence Taking Place? The cocitation patterns revealed a very mixed structure within the problem network between 1976 and 1987 (T1 and $\mathrm{T} 2)$. Researchers representing very different approaches to the study of dyslexia were grouped together at $\mathrm{T} 1$ and $\mathrm{T} 2$, presumably reflecting a period of negotiation during the early stages of problem area development (Mulkay et al., 1975).

Attention had been focused on the visual approach to dyslexia through several high profile articles in the late 1970s, but the co-citedness of visual dyslexia authors at the same period was much lower than reports in the literature would lead one to expect. It may be that delays inherent in the publication cycle caused this mismatch between patterns in the literature and co-citedness, with co-citation patterns trailing behind. Alternatively, it may be that visual dyslexia researchers published in lesserknown journals or edited works outside the coverage of the ISI citation databases at this time, accounting for the low co-citation counts. However, if this were completely the case, one wonders how researchers from a more established perspective would have learned of their work. It is therefore likely that some combination of both factors is responsible for this finding.

Between 1989 and 1993 (T3), co-citation patterns revealed a much clearer structure, with two clearly defined blocks, which corresponds well with the proposed alternative perspectives in the problem area. As hypothesized, the mean strength of the links in the problem area increase over time. Co-citation data indicate a system of stratification within the dyslexia network as well. These findings are consistent with the model of branching described by Mulkay et al. (1975) (exploration, disarray, negotiation, emergence of an elite structure).

As hypothesized, the social network (who-to-whom network at T3) included researchers from both proposed perspectives, as well as those migrants who were outside the area at T1. However, when considered in conjunction with the divergence of co-citation patterns over time, it seems that several distinct lines of research may be going on within one or more social networks, as Lievrouw et al. (1987) found as well in their study of lipid researchers. 
Phonological sub-block

(Editorial board members)

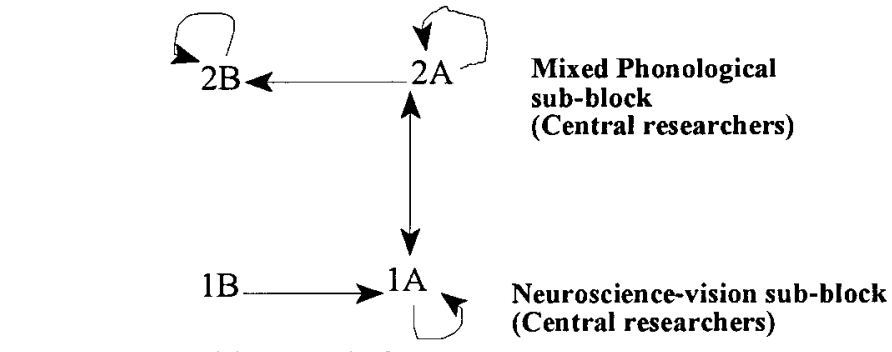

Neuroscience-vision sub-block

(Outsiders)

\section{Note: Arrows indicate the directionality of communication links: e.g., Sub-block $1 \mathrm{~B}$ communicates with $1 \mathrm{~A}$ but not with itself.}

FIG. 4. Reduced graph of informal (social) network relations at time three.

In summary, the results are consistent with Mulkay and co-workers' model of branching, but fail to support a clear pattern of convergence. It is possible that the dyslexia problem area is at an earlier stage of scientific growth than expected from an examination of the scientific literature in the field, and that it has only recently become more distinct in its intellectual structure. Alternatively, it may be that the co-citation methodology must be continued in a longitudinal follow-up in order to correct for the temporal lag which may be associated with the use of citation data in a rapidly changing problem area.

\subsection{Implications}

Support for the Model of Branching. The results provide strong support for a gradual process of scientific change, consistent with many aspects of descriptions by Chubin (1976, 1985), Gieryn (1978), Mulkay, Gilbert, and Woolgar (1975), Whitley (1984), Ziman (1987), and others. Although inflammatory rhetoric in the published literature on dyslexia might have implied the potential for revolutionary change such as that outlined by Kuhn (1970), a variety of measures indicate that a less well-accepted perspective (neuroscience-vision) has gradually assumed greater respectability within this hybrid field, and that such change is ongoing.

Validation and Analysis of Co-Citation Structure. The study provided firm support for the use of author cocitation and social network data to identify intellectual perspectives in a problem area. McCain (1986) and Lievrouw et al. (1987) used expert judgments to validate the co-citation maps of two specialty areas and grant term co-occurrence blocks, respectively. Mullins and colleagues (1977) compared a combination of measures (e.g., sociometric data, historical analyses, and social characteristics) with document co-citation blocks over time as part of the validation process. The present investigation extended these efforts by using self-report and biographical data to distinguish and validate the labels of network structures. The consistency of results, even during periods of transition, provides strong support for the use of co-citation data in studying alternative perspectives in a field, even while raising other questions concerning temporal lags in the data. Network analysis at both the two-block and four-block level permitted investigation of major trends in the data over time, as well as an opportunity to explore finer details of network structure and interaction. In particular, the finer level of analysis revealed insights about the role of more central researchers and editorial gatekeepers in the network.

Relationship of Intellectual and Social Structures. The present study showed that patterns of co-citation and social interaction are at best only very weakly associated. This finding is consistent with prior work by Lievrouw et al. (1987), although discrepancies between the cocitation patterns and reports in the literature suggest that the relationship may be further complicated by the "inertia" of aggregate co-citation data (McCain, 1986, p. 121). Upon consideration, the mismatch between social and intellectual structure is not as surprising as one might think. To begin with, the use of formal communication measures (e.g., citations) " "perpetuate a 'rationalized' view of the nature of science"' (Edge, 1979, p. 112) which obscures many of the key elements of the process of doing science, such as opinions, interests, and the character of the author, competition among scientists, and preferred methods and techniques of the problem area (Gilbert, 1976). Authors may cite papers for a variety of reasons (e.g., diplomacy, convenience, criti- 
cism, self-citation ) while possibly overlooking or omitting the most important influences on their work. Observations from practitioners who publish only rarely may provide the impetus for new directions in research, but might not be reflected in citation patterns at all. On the other hand, individuals may reference someone's work whom they have never met or communicated with in any way.

Overall, this study provided clear evidence for a process of evolution -as compared to revolution-in this particular hybrid area, to add to a growing family of studies on the process of change in scientific structures.

\section{Acknowledgments}

This research was partially supported by a grant to the senior author from the NYS/UUP Professional Development and Quality of Working Life Committee.

\section{References}

American Academy of Ophthalmology. (1987). Policy statement: Learning disabilities, dyslexia, and vision. Journal of Learning Disabilities, 20(7), 412-413.

Anderson, J. G., Jay, S. J., Schweer, H. M., Anderson, M. M., \& Kassing, D. (1987). Physician communication networks and the adoption and utilization of computer applications in medicine. In J. G. Anderson \& S. J. Jay (Eds.), Use and impact of computers in clinical medicine (pp. 185-199). New York: Springer-Verlag.

Bakker, D. J., Moerland, R., \& Goekoop-Hoetkens, M. (1981). Effects of hemisphere-specific stimulation on the reading performance of dyslexic boys: A pilot study. Journal of Clinical Neuropsychology, 3, 155-159.

Benton, A. L. (1975). Developmental dyslexia: Neurological aspects. Advances in Neurology, 7, 1-47.

Benton, A. (1985). Visual factors in dyslexia: An unresolved issue. In D. D. Duane \& C. K. Leong (Eds.), Understanding learning disabilities: International and multidisciplinary views (pp. 87-96). New York: Plenum Press.

Borgman, C. L., \& Rice, R. E. (1992). The convergence of information science and communication: A bibliometric analysis. Journal of the American Society for Information Science, 43, 397-411.

Breiger, R. L. (1976). Career attributes and network structure: A blockmodel study of a biomedical research specialty. American Sociological Review, 41, 117-135.

Breiger, R. L., Boorman, S. A., \& Arabie, P. (1975). An algorithm for clustering relational data with applications to social network analysis and comparison with multidimensional scaling. Journal of Mathematical Sociology, 12, 328-383.

Breitmeyer, B. G., \& Ganz, L. (1976). Implications of sustained and transient channels for theories of visual pattern masking, saccadic suppression and information processing. Perception, 83, 1-36.

Callon, M. (1995). Four models for the dynamics of science. In S. Jasanoff, G. E. Maarke, J. C. Petersen, \& T. Pinch (Eds.), Handbook of science and technology studies (pp. 29-63). Thousand Oaks, CA: Sage.

Chubin, D. E. (1976). The conceptualization of scientific specialties. Sociological Quarterly, 17, 448-476.

Chubin, D. E. (1985). Beyond invisible colleges: Inspirations and aspirations of post-1972 social studies of science. Scientometrics, 7, 221254.

Cottrill, C. A., Rogers, E. M., \& Mills, T. (1989). Co-citation analysis of the scientific literature of innovation research traditions. Knowledge: Creation, Diffusion, Utilization, 11, 181-208.

Crane, D. (1972). Invisible colleges: Diffusion of knowledge in scientific communities. Chicago: University of Chicago Press.

Eden, G. F., Stein, J. F., Wood, M. H., \& Wood, F. B. (1995). Verbal and visual problems in reading disability. Journal of Learning Disabilities, 28(5), 272-290.

Edge, D. (1979). Quantitative measures of communication in science: A critical review. History of Science, 7, 102-134.

Flax, N., Mozlin, R., \& Solan, H. A. (1984). Discrediting the basis of the AAO policy: Learning disabilities, dyslexia, and vision. Journal of the American Optometric Association, 55(6), 399-401.

Fletcher, J. M., \& Satz, P. (1979a). Has Vellutino led us astray? A rejoinder to a reply. Journal of Learning Disabilities, 12, 168-171.

Fletcher, J. M., \& Satz, P. (1979b). Unitary deficit hypotheses of reading disabilities: Has Vellutino led us astray? Journal of Learning Disabilities, 12, 156-159.

Galaburda, A. M. (Ed.). (1989). From reading to neurons. Cambridge, MA: MIT.

Galaburda, A. M. (1993). Neurology of developmental dyslexia. Current Opinion in Neurology and Neurosurgery, 6, 237-242.

Garvey, W. D. (1979). Communication: The essence of science. New York: Pergamon.

Gieryn, T. (1978). Problem retention and problem change in science. In J. Gaston (Ed.), Sociological inquiry: The sociology of science (pp. 96-115). San Francisco: Jossey-Bass.

Gilbert, G. N. (1976). The transformation of research findings into scientific knowledge. Social Studies of Science, 6, 281-306.

Knoke, D., \& Kuklinski, J. H. (1982). Network analysis. Newbury Park, CA: Sage.

Kruk, R. S. (1991). Functional consequences of a transient visual processing deficit in reading disabled children. Unpublished doctoral dissertation, University of Toronto, Toronto, Canada.

Kuhn, T. (1970). The structure of scientific revolutions. Chicago: University of Chicago Press.

Laumann, E. O., Marsden, P. V., \& Prensky, D. (1983). The boundary specification problem in network analysis. In R. S. Burt \& M. J. Minor (Eds.), Applied network analysis: A methodological introduction (pp. 18-34). Beverly Hills, CA: Sage.

Lehmkuhle, S., Garzia, R. P., Turner, L., Hash, T., \& Baro, J. A. (1993). A defective visual pathway in children with reading disability. New England Journal of Medicine, 328, 989-996.

Lievrouw, L. A. (1990). Reconciling structure and process in the study of scholarly communication. In C. L. Borgman (Ed.), Scholarly communication and bibliometrics (pp. 59-69). Newbury Park, CA: Sage.

Lievrouw, L. A., Rogers, E. M., Lowe, C. U., \& Nadel, E. (1987). Triangulation as a research strategy for identifying invisible colleges among biomedical scientists. Social Networks, 9, 217-248.

Livingstone, M. S., Rosen, G. D., Drislane, F. W., \& Galaburda, A. M. (1991). Physiological and anatomical evidence for a magnocellular defect in developmental dyslexia. Proceedings of the National Academy of Science, 88, 7943-7947.

Lovegrove, W., Martin, F., \& Slaghuis, W. (1986). A theoretical and experimental case for a visual deficit in specific reading disability. Cognitive Neuropsychology, 3, 225-267.

Lyon, G. R. (1991). Research in learning disabilities (Tech. Rep.). Bethesda, MD: The National Institute of Child Health and Human Development.

McCain, K. W. (1984). Longitudinal author cocitation mapping: The changing structure of macroeconomics. Journal of the American Society for Information Science, 35, 351-359.

McCain, K. W. (1986). Cocited author mapping as a valid representation of intellectual structure. Journal of the American Society for Information Science, 37, 111-122.

McCain, K. W. (1989). Mapping authors in intellectual space: Population genetics in the 1980s. Communication Research, 16(5), 667681.

McCain, K. W. (1990a). Mapping authors in intellectual space: A tech- 
nical overview. Journal of the American Society for Information Science, 41, 433-443.

McCain, K. W. (1990b). Mapping authors in intellectual space: Population genetics in the 1980s. In C. L. Borgman (Ed.), Scholarly communication and bibliometrics (pp. 194-216). Newbury Park, CA: Sage.

Mulkay, M. J. (1976). The model of branching. Sociological Review, 24, 125-133.

Mulkay, M. J. (1977). Sociology of the scientific research community. In I. Spiegel-Rosing \& D. de Solla Price (Eds.), Science, technology and society: A cross-disciplinary perspective (pp. 93-148). Beverly Hills, CA: Sage.

Mulkay, M. J., Gilbert, G. N., \& Woolgar, S. (1975). Problem areas and research networks in science. Sociology, 9, 187-203.

Mullins, N. C., Hargens, L. L., Hecht, P. K., \& Kick, E. L. (1977). The group structure of cocitation clusters: A comparative study. American Sociological Review, 42, 552-562.

Noreika, J. C. (1990). The oversupply of ophthalmic practitioners. American Journal of Ophthalmology, 109, 593-597.

Paisley, W. (1990). An oasis where many trails cross: The improbable cocitation networks of a multidiscipline. Journal of the American Society for Information Science, 41, 459-468.

Pennington, B. F. (1991). Diagnosing learning disorders: A neuropsychological framework. New York: Guilford Press.

Perry, C. A., \& Rice, R. E. (1997). Network influences in the hybrid problem area of developmental dyslexia: Characteristics affecting involvement. Manuscript in preparation.

Pierce, S. J. (1990). Disciplinary work and interdisciplinary areas: Sociology and bibliometrics. In C. L. Borgman (Ed.), Scholarly communication and bibliometrics (pp. 46-58). Newbury Park, CA: Sage.

Rappa, M. A., \& Debackere, K. (1995). An analysis of entry and persistence among scientists in an emerging field. $R \& D$ Management, 25, $323-341$.

Rayner, K. (1993). Visual processes in reading: Directions for research and theory. In D. M. Willows, R. S. Kruk, \& E. Corcos (Eds.), Visual processes in reading and reading disabilities (pp. 475-480). Hillsdale, NJ: Lawrence Erlbaum Associates.

Rayner, K., \& Pollatsek, A. (1989). The psychology of reading. Englewood Cliffs, NJ: Prentice-Hall.

Restivo, S., \& Loughlin, J. (1987). Critical sociology of science and scientific validity. Knowledge: Creation, Diffusion, Utilization, 8, 486-508.

Rice, R. E., \& Richards, W., Jr. (1985). An overview of communication network analysis programs and methods. In B. Dervin \& M. Voight (Eds.), Progress in communication sciences (Vol. 6, pp. 105-165). Norwood, NJ: Ablex.

Rogers, E. M. (1983). Diffusion of innovations. New York: Free Press.

Rogers, E. M., \& Cottrill, C. A. (1990). An author co-citation analysis of two research traditions: Technology transfer and the diffusion of innovations. In C. L. Borgman (Ed.), Scholarly communication and bibliometrics (pp. 157-165). Newbury Park, CA: Sage.

Shaywitz, S. E., Shaywitz, B. A., Fletcher, J. M., \& Escobar, M. D. (1990). Prevalence of reading disability in boys and girls: Results of the Connecticut Longitudinal Study. JAMA, 264, 998-1002.

Solan, H. A. (1993). Dyslexia and learning disabilities: An overview. Optometry and Vision Science, 70(5), 343-347.

Stanovich, K. E. (1979). The effect of orthographic structure on the word search performance of good and poor readers. Journal of Experimental Child Psychology, 28, 258-267.

Stanovich, K. E. (1985). Explaining the variance in reading ability in terms of psychological processes: What have we learned? Annals of Dyslexia, 35, 67-96.

Stanovich, K. E. (1993). Introduction. In D. M. Willows, R. S. Kruk, \& E. Corcos (Eds.), Visual processes in reading and reading disabilities (pp. xxi-xxiii). Hillsdale, NJ: Lawrence Erlbaum Associates.

Swanson, D. R. (1990). The absence of co-citation as a clue to undiscovered causal connections. In C. L. Borgman (Ed.), Scholarly communication and bibliometrics (pp. 129-137). Newbury Park, CA: Sage.

Tallal, P., Galaburda, A. M., Llinas, R. R., \& von Euler, C. (Eds.). (1993). Temporal information processing in the nervous system: Special reference to dyslexia and dysphasia (Annals of the New York Academy of Sciences, Vol. 682). New York: New York Academy of Sciences.

Vellutino, F. R. (1979). The validity of perceptual deficit explanations of reading disability: A reply to Fletcher and Satz. Journal of Learning Disabilities, 12, 160-167.

Vellutino, F. R. (1987). Dyslexia. Scientific American, 256(3), 34-41.

Vellutino, F. R., Steger, B. M., Moyer, S. C., Harding, C. J., \& Niles, J. A. (1977). Has the perceptual deficit hypothesis led us astray? Journal of Learning Disabilities, 10, 375-385.

Walker, A., Jr. (Ed.). (1994). Thesaurus of psychological index terms. Washington, DC: American Psychological Association.

Wasserman, S., \& Faust, K. (1994). Social network analysis: Methods and applications. New York: Cambridge University Press.

White, H. D. (1990). Author co-citation analysis: Overview and defense. In C. L. Borgman (Ed.), Scholarly communication and bibliometrics (pp. 84-106). Newbury Park, CA: Sage.

White, H. C., Boorman, S. A., \& Breiger, R. L. (1976). Social structure from multiple networks: I. Blockmodels of roles and positions. American Journal of Sociology, 81, 730-780.

White, H. D., \& Griffith, B. C. (1981). Author cocitation: A literature measure of intellectual structure. Journal of the American Society for Information Science, 32, 163-171.

Whitley, R. (1984). The intellectual and social organization of the sciences. Oxford: Clarendon Press.

Ziman, J. M. (1987). The problem of "problem choice." Minerva, 25, 92-106. 